\title{
Federalismo e Relações Intergovernamentais no Brasil: A Reforma de Programas Sociais*
}

\author{
Marta Arretche
}

\begin{abstract}
A literatura comparada contemporânea considera que as características institucionais dos estados federativos operam no sentido de restringir as possibilidades de mudança do status quo. A afirmação central é que a natureza das relações vertical e horizontal em estados federativos dispersa a autoridade política e potencializa o poder de veto das minorias.

No plano das relações verticais, Lijphart afirma que o federalismo

“[...] pode ser considerado o mais típico e drástico método de divisão do poder [pois] divide o poder entre níveis inteiros de governo. [...] Em todas as democracias, o poder é necessariamente dividido em alguma extensão entre governos centrais e não centrais, mas esta divisão é inteiramente unilateral nas democracias majoritárias. Para man-
\end{abstract}

\footnotetext{
* Agradeço ao Grupo de Política do Cebrap e aos participantes do Seminário Temático "Federalismo, Instituições e Políticas Públicas no Brasil" da ANPOCs de 2001 as críticas e comentários à primeira versão deste texto, particularmente a Argelina Figueiredo, Maria Hermínia Tavares de Almeida, Fernando Limongi, Celina Souza, Eduardo Marques, Vera Schattan Coelho e Haroldo Torres. Agradeço a Mara Roberta de Souza, bolsista PIBIC/CNPq, o competente trabalho de coleta de dados estatísticos. Finalmente, os comentários dos pareceristas anônimos de Dados foram fundamentais para a elaboração da versão final deste artigo.
}

DADOS - Revista de Ciências Sociais, Rio de Janeiro, Vol. 45, nํ3, 2002, pp. 431 a 458. 


\section{Marta Arretche}

ter a regra majoritária no modelo majoritário puro, o governo central deve controlar não apenas o aparato do governo central mas também todos os governos não centrais, potencialmente competitivos. O governo majoritário é, portanto, ao mesmo tempo unitário (não federal) e centralizado. O modelo consensual é inspirado no objetivo oposto. Seus métodos são federalismo e descentralização - isto é, não apenas uma divisão garantida de poder entre os níveis de governo central e não central, mas também, na prática, fortes governos não centrais que exercem uma porção substancial do total do poder disponível em ambos os níveis" (1999:185-186).

A baixa integração vertical implicaria limites à capacidade de coordenação do governo central, pois

"[...] governos provinciais e federais podem ter autoridade para intervir em uma área de política sem permissão do outro nível de governo. [...] este tipo de federalismo [...] corre o risco de os diferentes níveis de governo tenderem a impor conflitos entre programas, a elevar os custos da implementação e a tornar o problema da coordenação de objetivos ainda mais difícil." (Weaver e Rockman, 1993:459)

No plano das relações horizontais, a representação dos estados em uma Câmara Federal, juntamente com as restrições para emendar a Constituição e os poderes da Suprema Corte, operam no sentido de assegurar a divisão federal de poder (Lijphart, 1999:187-188), reiterando, assim, a dispersão da autoridade política. O poder de veto das minorias pode variar de acordo com os poderes constitucionais da Câmara Alta e com o grau de super-representação dos estados menores (Lijphart, 1984), mas, de qualquer modo, a presença de um maior número de veto players institucionalizados nas arenas decisórias aumenta o potencial de estabilidade das políticas existentes (Tsebelis, 1997).

A dispersão da autoridade afeta também o conteúdo das decisões tomadas, na medida em que as garantias institucionais dos Estadosmembros no processo decisório tendem a produzir deliberações políticas com base no "mínimo denominador comum" (Pierson e Leibfried, 1995) $)^{1}$.

Comparado com outras federações contemporâneas, o Brasil estaria juntamente com os EUA - no extremo da escala de demos-constraining, isto é, um tipo de federalismo cujas instituições políticas conforma- 
riam processos decisórios fortemente restritivos à manifestação da vontade da maioria (expressa na escolha do presidente). Em primeiro lugar, a super-representação dos estados menores na Câmara dos Deputados, combinada aos excessivos poderes legislativos do Senado, exponenciariam o poder de veto dos estados menores ${ }^{2}$. Além disso, o poder residual dos estados nos casos de omissão constitucional, o excessivo detalhamento da Constituição de 1988 e a exigência de supermaiorias para as emendas constitucionais ofereceriam aos estados oportunidades adicionais de veto às iniciativas de reforma da Presidência (Stepan, 1999) ${ }^{3}$. A conseqüência dessa engenharia institucional é que

“[...] mesmo ao se defrontar com a oposição da sociedade, os presidentes [brasileiros] puderam implementar as políticas de sua preferência quando encontraram baixa resistência institucional, mas não foram capazes de fazê-lo quando o Congresso e/ou os governos foram jogadores decisivos" (Mainwaring, 1997:102).

Os presidentes brasileiros ficariam imobilizados nas áreas de política em que o Congresso e os governadores são veto players decisivos (idem; Abrucio, 1998; Stepan, 1999; Samuels, 2000; Ames, 2001). Seriam, assim, duas as situações mais prováveis nas iniciativas de reforma que afetariam os interesses dos estados no Brasil: (a) impasse ou paralisia decisória e/ou (b) subordinação das preferências do governo federal àquelas dos governos estaduais e/ou municipais.

Essas previsões não são confirmadas pelas evidências apresentadas aqui. Em quatro áreas de política social - educação fundamental, saúde, habitação e saneamento--, o governo federal encontrou resultados diversos na implementação da agenda de reformas que afetavam diretamente os interesses de estados e municípios. Entretanto, nem o impasse nem a subordinação do governo federal às preferências dos governos locais caracterizaram os casos examinados. Em outras palavras, diferentemente das previsões da literatura que enfatiza o poder de veto dos governos subnacionais no federalismo brasileiro, estes últimos não representaram um ponto de veto intransponível à implementação da agenda de reformas do governo federal nessas políticas particulares.

Este artigo pretende demonstrar que, (i) na ausência de imposições constitucionais, a autonomia política dos governos locais - inerente aos estados federativos -, de fato, potencializa o poder de veto desses 
governos à implementação de políticas propostas pelo Executivo federal. Isto implica que, para obter a adesão dos governos locais, o Executivo federal deve incorporar suas demandas às políticas que envolvam relações intergovernamentais. A incorporação de pelo menos uma parte dessas demandas, somada ao compromisso crível de cumpri-las, permite ao Executivo federal contornar o poder de veto dos governos locais no plano das relações verticais.

No plano das relações horizontais, (ii) a literatura que enfatiza o poder de veto dos governos locais na arena congressual brasileira minimiza a importância dos recursos de poder do Executivo federal, tais como os poderes de agenda e de veto, assim como o controle sobre recursos necessários à sobrevivência política dos parlamentares ( $\mathrm{Fi}$ gueiredo e Limongi, 1999; 2002). Além disso, ao contrário do que afirma Stepan (1999), (iii) no Brasil, a aprovação de emendas constitucionais é muito mais fácil do que nos Estados Unidos, porque, como nossas regras não incluem a necessidade de ratificação das assembléias estaduais, a autoridade constitucional dos estados brasileiros é muito mais reduzida do que a dos estados norte-americanos. Nos Estados Unidos, emendas à Constituição, mesmo que não afetem a distribuição federal de poderes, exigem a ratificação de três quartos dos Estados-membros, e há mesmo tipos de emendas que não podem ser aprovadas sem a ratificação de 49 dos 50 estados (Duchacek, 1970:231) .

Entretanto, (iv) a categoria "federalismo" é insuficiente para definir o potencial de estabilidade de políticas particulares. Este é condicionado pela forma como estão estruturadas as relações intergovernamentais nas políticas específicas ${ }^{5}$. Em outras palavras, o poder de veto dos governos locais às iniciativas federais varia de acordo com as políticas. Mais particularmente, (v) regras constitucionais, legados de políticas prévias e o ciclo da política estruturam diferentemente as arenas decisórias, condicionando as estratégias e as chances de sucesso dos atores federativos ${ }^{6}$.

\section{AS REFORMAS NAS POLÍTICAS SOCIAIS BRASILEIRAS E SUAS ARENAS}

\section{Políticas de Habitação e Saneamento}

Nas áreas de habitação e saneamento, a mudança do paradigma de política pública ${ }^{7}$ do regime militar somente ocorreu no governo Fernando Henrique Cardoso. Nenhum dos governos democráticos ante- 
riores tinha uma agenda de reformas que visasse modificar radicalmente o modelo de política anterior.

Quer para a política de habitação social quer para o saneamento básico, o modelo do regime militar era simultaneamente estatal e centralizado. A oferta de bens e serviços fazia-se via produção pública - a habitação social e os serviços de saneamento básico eram geridos por empresas estatais. No plano federal, havia uma agência que centralizava a formulação das políticas e a arrecadação da principal fonte de financiamento da política, o Fundo de Garantia por Tempo de Serviço - FGTS. Com base nesse modelo, constituiu-se no país uma rede de 44 empresas públicas municipais e estaduais de habitação social, assim como 27 companhias estaduais de saneamento ${ }^{8}$.

A agenda de reformas do governo Fernando Henrique Cardoso visou rever esse paradigma: descentralizar a alocação dos recursos federais e introduzir princípios de mercado na provisão de serviços, mais particularmente abrir espaço para a participação do setor privado nessa área e introduzir uma política de crédito para o mutuário final.

Esses objetivos de reforma decorriam de uma avaliação negativa dos resultados do modelo anterior. O Executivo federal avaliava que a corrupção e ineficiência administrativas das gestões civis precedentes foram possíveis graças à centralização federal'; por conseguinte, era forte a concepção, derivada desta primeira, que associava positivamente descentralização a formas mais ágeis, democráticas e eficientes de gestão. A defesa da descentralização era ainda reforçada pela avaliação de que a burocracia federal estava viciada nos padrões administrativos prévios. Além disso, o Executivo federal considerava que o modelo anterior gerava incentivos à ineficiência das prestadoras estaduais e municipais. Políticas tarifárias voltadas a satisfazer o eleitorado, renegociação sistemática das dívidas com o governo federal, empreguismo e uma burocracia ativa na defesa de seus próprios interesses eram o resultado do modelo anterior. A separação entre regulação (estatal) e provisão (privada ou pública com padrões privados de eficiência) seria a alternativa mais adequada.

Por fim, na política social de habitação, o financiamento à produção do modelo anterior implicava que o crédito hipotecário só podia ser obtido para imóveis cuja produção tivesse sido financiada pelo sistema. Como nesse modelo não é o mutuário quem tem o financiamento, 
e sim o imóvel que será objeto da compra, a conseqüência direta é a reduzida margem de escolha do mutuário final no mercado imobiliário, assim como a impossibilidade de ativar o mercado de imóveis usados. A ausência de financiamento direto ao mutuário final, habilitando-o a adquirir um imóvel diretamente no mercado, era uma das principais críticas - inclusive de setores da esquerda - ao modelo anterior.

\section{Desestatização das empresas públicas de habitação e saneamento}

Em 1995, já no primeiro ano da gestão do ministro José Serra no Ministério do Planejamento e Orçamento, os governadores de estado foram contemplados com a possibilidade de ter grande autoridade sobre a alocação de suas respectivas parcelas do fundo público federal para o desenvolvimento urbano, o FGTS ${ }^{10}$. Para aderir ao programa, os governadores deveriam constituir comissões estaduais, com representação paritária entre governo do estado, governos municipais e sociedade civil. Eles contavam com grande autonomia na composição dessas comissões, o que permitiu um comportamento generalizado de montagem de comissões passíveis de controle no processo decisório de seleção de projetos.

Na história das políticas públicas no Brasil, esse deve estar entre os programas com maior velocidade de implantação: em apenas quatro meses, todos os estados brasileiros haviam aderido a ele. Na base desse sucesso estão suas regras de operação: a definição de uma estrutura de incentivos que tornou extremamente atraente a adesão dos governadores ao programa federal.

A descentralização da autoridade para alocação desses recursos, entretanto, foi combinada com um endurecimento das exigências para a obtenção dos empréstimos federais. Mesmo que aprovada pela comissão estadual, por uma empresa pública estadual ou municipal, ou mesmo um governo estadual ou municipal, somente poderia receber um financiamento caso comprovasse capacidade de endividamento. Assim, no quadro de endividamento generalizado de meados dos anos 90, somente aquelas empresas públicas que tivessem sucesso nas medidas de saneamento de suas finanças obteriam os empréstimos federais. 
Essa medida dividia os governadores entre aqueles que "estavam fazendo a sua lição de casa" e aqueles que resistiam a adotar medidas de contenção do déficit público; bem como criava incentivos para a reestruturação das empresas públicas de habitação e saneamento. Empresas públicas já excessivamente endividadas com o governo federal - que tinha sido de longe o maior emprestador até então - passaram a ser objeto de uma política de desfinanciamento.

No debate público, o governo federal argumentava que o FGTS, baseado na folha de salários e destinado também a indenizar trabalhadores demitidos sem justa causa, sofria as conseqüências do desemprego e do baixo nível dos salários. Seu caráter pró-cíclico erodia a possibilidade de realizar a universalização dos serviços exclusivamente com base em recursos públicos. Para isto, seria necessário atrair recursos do setor privado, abrindo as empresas estatais - particularmente as de saneamento - a formas de terceirização e privatização dos serviços.

Entretanto, por causa do endurecimento das condições de empréstimo e da política de desfinanciamento, acumulava-se um saldo muito elevado de recursos não aplicados do FGTS. Em 1997, este saldo era de $R$ \$ 9,5 bilhões (Pinheiro, 1998), algo equivalente a mais da metade da arrecadação bruta anual do Fundo em 1996 e 1997.

Paralelamente, dois bancos federais de fomento abriram linhas de crédito para financiar as privatizações na área de saneamento. O Banco Nacional de Desenvolvimento Econômico e Social - BNDES financiou algumas das privatizações municipais e adiantou recursos para a privatização de uma companhia estadual, e a Caixa Econômica Federal-CEF foi autorizada, em 1997, pelo Conselho Curador do FGTS, a criar um programa por meio do qual os recursos do Fundo poderiam ser utilizados para financiar as privatizações das companhias de saneamento.

A estratégia do desfinanciamento decorreu, simultaneamente, da impossibilidade de interferência direta do Executivo federal nas empresas públicas de saneamento e habitação e de sua função de principal financiador da política, ambas herdadas do modelo anterior. Na fase de expansão e consolidação da rede prestadora de serviços, ao longo dos anos 70, havia se constituído uma rede de empresas de propriedade pública estadual e municipal. Dada a autonomia política dos go- 
vernos locais, qualquer política do governo federal nessa área teria de contar com a adesão deles. Entretanto, a função de financiador do Executivo federal permitiu-lhe adotar a estratégia do desfinanciamento, cujos efeitos seriam indiretos e pouco visíveis ao debate público.

Na área de habitação, entre 1995 e 2000, doze das 44 Companhias de Habitação - COHABS declararam falência ou diversificaram suas atividades, passando a operar como institutos de desenvolvimento urbano e não mais como agências de promoção pública de habitações para baixa renda ${ }^{11}$.

Na área de saneamento, a privatização das empresas estaduais era uma alternativa atraente para certos governadores e prefeitos. Alguns compartilhavam da mesma avaliação negativa do governo federal em relação à prestação pública de serviços, especialmente do fato de essas empresas terem gerado burocracias autônomas e politicamente ativas sobre as quais a autoridade política tinha reduzido poder de controle. Outros, premidos por problemas fiscais, viam na venda de suas empresas uma alternativa seja para reduzir o déficit público seja para arrecadar recursos que poderiam ser empregados com maior liberdade alocativa. Iniciou-se, assim, na segunda metade dos anos 90, uma onda de tentativas de privatização de companhias municipais e estaduais de saneamento ${ }^{12}$ nos estados do Rio de Janeiro, Espírito Santo, Paraná e Ceará, bem como em algumas cidades como Fortaleza (CE), Limeira (SP) e Cajamar (SP).

Nos municípios, o único ponto de veto à privatização das empresas municipais seria a Câmara Municipal. O reduzido número de pontos de veto associado ao interesse dos prefeitos nas privatizações permitiriam esperar uma significativa taxa de sucesso dessas iniciativas. No entanto, Sanchez (2000) demonstra que, no Estado de São Paulo, entre 1995 e 1998, a pressão - da opinião pública e da companhia estadual interessada em disputar esse mercado com as possíveis prestadoras privadas - sobre as Câmaras Municipais inviabilizou a maior parte das tentativas municipais de privatização.

As tentativas de privatização das empresas estaduais, cuja iniciativa cabia aos governadores, foram enormemente dificultadas pela configuração de arenas decisórias caracterizadas por um elevado número de pontos de veto e baixa coesão dos atores envolvidos. Grande parte 
dos obstáculos para a privatização ou flexibilização dos serviços (isto é, a transferência de apenas parte dos sistemas a um prestador privado) decorreu da pulverização de titularidade no setor saneamento, a qual, por sua vez, é derivada de uma regra constitucional.

A interpretação dominante sobre o artigo 30 da Constituição Federal de 1988 é a de que as atividades de saneamento básico são de responsabilidade municipal ${ }^{13}$. As empresas estaduais de saneamento operam os serviços como concessionárias, com base em contratos firmados ao longo dos anos 70 e 80 . Assim, ainda que uma companhia estadual possa vender seus ativos, este ato não implicaria a autorização para um terceiro operar os serviços concedidos pelos municípios às companhias estaduais. Neste caso, com base na interpretação dominante sobre a regra constitucional, a privatização de uma companhia estadual de saneamento (ou de um sistema ou subsistema de serviços) dependeria da aprovação de todas as Câmaras Municipais onde a companhia é concessionária. As tentativas de privatização das empresas estaduais foram marcadas pelas dificuldades de os Executivos estaduais superarem o recurso ao princípio de titularidade por parte de empregados das empresas estaduais, de prefeitos e de vereadores das diversas Câmaras Municipais ${ }^{14}$.

Em 1996, o então senador José Serra encaminhou ao Senado um projeto de lei (PL 266/96) que, caso aprovado, dispensaria o governo do estado da autorização dos municípios nas privatizações em conurbações e regiões metropolitanas. Entretanto, este projeto foi considerado inconstitucional na Comissão de Constituição e Justiça do Senado.

Nessas condições, caso a privatização na área de saneamento estivesse entre as prioridades do Executivo federal, o passo seguinte deveria ser o encaminhamento de uma proposta de emenda constitucional. Mas esta iniciativa não foi tomada.

\section{A mudança do modelo de política social de habitação}

Na área de habitação social, o Executivo federal criou duas linhas de financiamento em 1995. A primeira, o Programa Pró-Moradia, pode ser considerada uma continuação do modelo anterior. Voltado para a população de até três salários-mínimos, este programa contaria com a intermediação de agentes promotores públicos, prefeituras e órgãos da administração direta e indireta para a construção ou melhoria de 
unidades habitacionais ou para a execução de modalidades diversas de infra-estrutura urbana. O desenho institucional da segunda linha de financiamento, o Programa Carta de Crédito Individual, entretanto, rompia com o paradigma do modelo anterior. Dirigido à população de até doze salários-mínimos, deveria conceder financiamentos diretamente ao mutuário final para que este pudesse adquirir uma moradia nova ou usada, ou mesmo construir ou reformar a sua. Trata-se de um programa de financiamento à demanda habitacional, cuja principal característica é permitir ao mutuário adquirir um imóvel diretamente no mercado imobiliário.

Entre 1995 e 1998, a rede de empresas públicas de habitação recebeu 11,5\% dos recursos do FGTS, via Programa Pró-Moradia, e 28\% dos recursos destinados ao Programa Carta de Crédito Associativo. O Programa de Carta de Crédito Individual, por sua vez, recebeu 76\% desses recursos, utilizados majoritariamente para a aquisição de imóveis usados (Tabelas 1, 2 e 3). Portanto, via gestão seletiva das linhas de crédito, ocorreu uma inflexão significativa na política habitacional: de um modelo centrado no financiamento à produção de habitações novas, e assentado em uma rede de prestadoras públicas, para um modelo centrado no financiamento ao mutuário final e, particularmente, destinado à aquisição de imóveis usados.

A alteração radical do modelo de financiamento à aquisição da casa própria contou com o apoio dos mutuários, pois a nova modalidadeuma antiga reivindicação de diversos críticos do modelo anterior amplia significativamente a liberdade de escolha do pretendente no

Tabela 1

Distribuição dos Recursos do FGTS por Programa Habitacional

(1995-1998)

$(\mathrm{em} R \$ 1.000,00)$

\begin{tabular}{l|c|c}
\hline Programa & Valor Contratado & $\%$ \\
\hline Pró-Moradia & $772.953,00$ & 11,41 \\
Carta de Crédito Individual & $5.136 .520,00$ & 75,80 \\
Carta de Crédito Associativo & $821.207,00$ & 12,12 \\
Apoio à Produção & $45.197,00$ & 0,67 \\
\hline Total & $\mathbf{6 . 7 7 5 . 8 7 7 , 0 0}$ & $\mathbf{1 0 0}$ \\
\hline
\end{tabular}

Fonte: Base de Dados da Caixa Econômica Federal - 30/6/1999.

Extraído de: USP / EESC/FIPAI (2000). 
Tabela 2

Programa Carta de Crédito Individual

Valores Contratados Globais por Modalidade

(1995-1998)

(em R\$ 1.000,00)

\begin{tabular}{l|c|c}
\hline Modalidades & Valor Contratado & $\%$ \\
\hline Ampliação & $48.944,00$ & 1 \\
Lotes & $55.856,00$ & 1 \\
Conclusão & $27.741,00$ & 1 \\
Construção & $311.325,00$ & 6 \\
Cesta & $347.259,00$ & 7 \\
Usado & $3.486 .910,00$ & 68 \\
Novo & $352.402,00$ & 7 \\
Terreno + Construção & $504.798,00$ & 10 \\
Remanescentes & $1.279,00$ & 0 \\
\hline Total & $\mathbf{5 . 1 3 6 . 5 1 4 , 0 0}$ & $\mathbf{1 0 0}$ \\
\hline
\end{tabular}

Fonte: USP/EESC/FIPAI (2000).

Tabela 3

Programa Carta de Crédito Associativo

Distribuição das Contratações por Tipo de Agente Promotor

(1995-1998)

(em R\$ 1.000,00)

\begin{tabular}{l|c|c|c|c}
\hline Promotor & $\begin{array}{c}\text { Valor do } \\
\text { Empréstimo }\end{array}$ & $\%$ & No Unidades & $\%$ \\
\hline Companhias habitacionais & $173.233,00$ & 21 & 15.155 & 28 \\
Entidades associativas & $647.974,00$ & 79 & 38.593 & 72 \\
\hline Total & $\mathbf{8 2 1 . 2 0 7 , 0 0}$ & $\mathbf{1 0 0}$ & $\mathbf{5 3 . 7 4 8}$ & $\mathbf{1 0 0}$ \\
\hline
\end{tabular}

Fonte: USP/EESC/FIPAI (2000).

mercado imobiliário. Desse modo, a estratégia de desfinanciamento das empresas públicas, via gestão seletiva dos financiamentos habitacionais, encontrava suporte político entre os beneficiários da política habitacional.

A gestão seletiva das linhas de financiamento não foi um resultado não intencional, derivado da exigência de adimplência junto ao go- 
verno federal para obtenção de recursos do FGTS, isto é, o desfinanciamento das empresas públicas não foi resultado apenas das taxas de inadimplência das prestadoras públicas. A meta de prioridade de aplicação de recursos no Programa de Carta de Crédito em detrimento do Programa Pró-Moradia foi objeto de uma resolução do Conselho Curador do FGTS (no 246) já em 1996. Assim, o desfinanciamento das empresas públicas fez parte de uma estratégia cujo objetivo central era introduzir mecanismos de mercado na gestão das políticas de desenvolvimento urbano.

A principal arena para aprovação das medidas necessárias à implementação dessa estratégia foi o Conselho Curador do FGTS. Conforme legislação aprovada no final dos anos $80^{15}$, este Conselho é o órgão encarregado de estabelecer as diretrizes e os programas de alocação de recursos do Fundo. Ele conta com uma representação de empregados e empregadores, mas não possui representação de estados e municípios. Em outras palavras, ainda que suas decisões sejam fundamentais para o financiamento das políticas de desenvolvimento urbano dos governos locais, o Conselho não é uma arena com representação federativa ${ }^{16}$, o que significa que estados e municípios não têm poder de veto nessa arena decisória. Na verdade, esta é uma arena cujos custos de negociação são bastante reduzidos para o governo fede$\mathrm{ral}^{17}$.

\section{Reforma Constitucional para o Ensino Fundamental}

Entre 1997 e 2000, ocorreu no Brasil uma significativa redistribuição das matrículas no nível fundamental de ensino. A matrícula total do setor público cresceu $6,7 \%$ no período, ao passo que as matrículas oferecidas pelos municípios aumentaram $34,5 \%$ e as estaduais tiveram crescimento negativo $(-12,4 \%)$ (ver Tabela 4$)$. Isto significa que ocorreu uma expressiva transferência das matrículas até então oferecidas pelos governos estaduais para os governos municipais. Os governos locais também alteraram seu comportamento para com os docentes: no período, ocorreu um crescimento global de $10 \%$ no número de professores e um aumento médio de $29,5 \%$ em sua remuneração. Na região Nordeste, esta elevação média foi de 59,7\% e, na região Norte, de $35 \%$ (Semeghini, s/d).

O súbito interesse dos municípios em oferecer matrículas no ensino fundamental e em aumentar os salários dos professores deveu-se a 
Federalismo e Relações Intergovernamentais no Brasil...

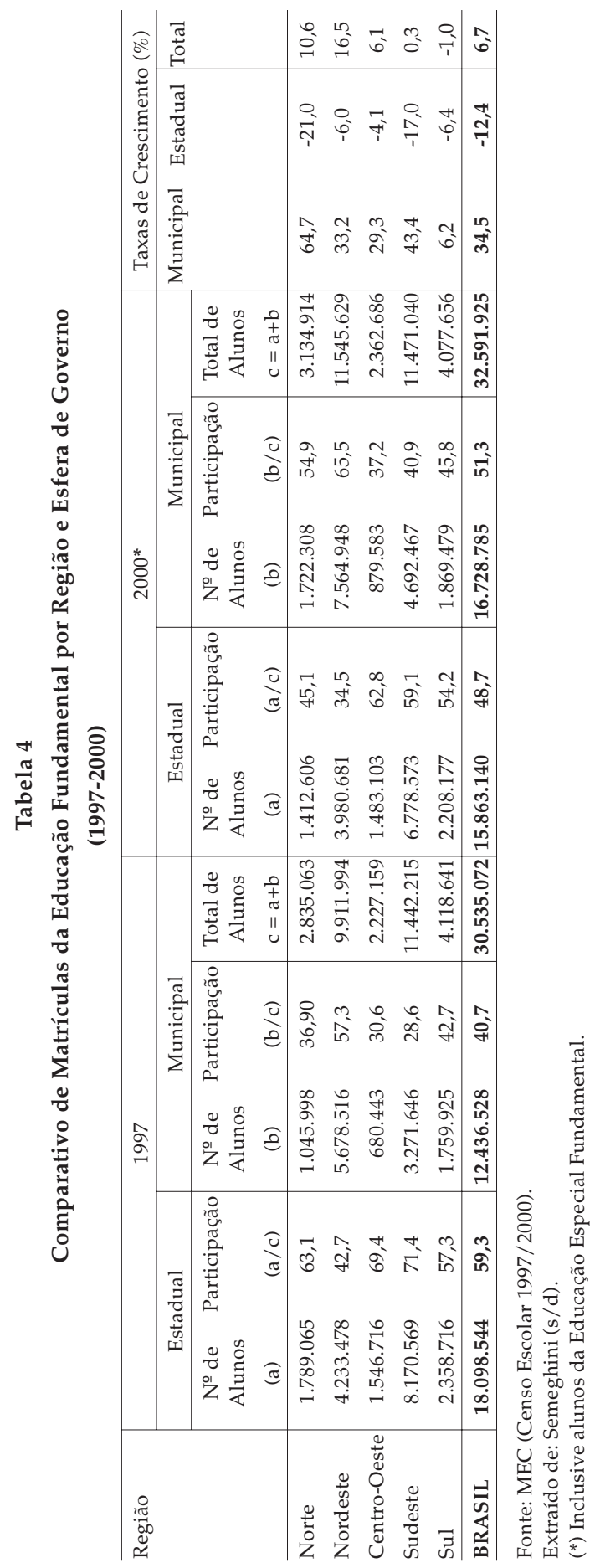


uma minirreforma tributária de âmbito estadual, produzida pela aprovação da emenda constitucional que criou o Fundo de Manutenção e Desenvolvimento do Ensino Fundamental e de Valorização do Magistério - FUNDEF. A Constituição Federal de 1988 havia estabelecido que a oferta de matrículas no nível fundamental deveria ser universal e oferecida preferencialmente pelos governos municipais. Além disso, obrigava governos estaduais e municipais a gastar $25 \%$ de suas receitas de impostos e transferências em ensino. Essa regra de vinculação de gastos deu origem a uma expansão generalizada - por parte de governos estaduais e municipais - da oferta de matrículas em todos os níveis de ensino - infantil, fundamental, médio e, até mesmo, superior. Além disso, a flexibilidade da regra constitucional permitiu que a expansão desse gasto se direcionasse para outras atividades afins, tais como financiamento de bolsas de estudo, transporte escolar etc. Particularmente nas regiões Sul e Sudeste, onde os governos estaduais já tinham uma participação importante na oferta de matrículas no ensino fundamental, a expansão de gastos dos municípios voltou-se vigorosamente para o ensino infantil.

Para promover a municipalização e a valorização salarial dos professores (vale dizer, aqueles que exercem diretamente atividades em sala de aula nesse nível de ensino), técnicos do Ministério da Educação - sem consulta ou negociação com estados e municípios - elaboraram um projeto de emenda constitucional que previa que, pelo prazo de dez anos, estados e municípios deveriam aplicar, no mínimo, 15\% de todas as suas receitas exclusivamente no ensino fundamental. Além disso, 60\% desses recursos deveriam ser aplicados exclusivamente no pagamento de professores no efetivo exercício do magistério. Para garantir padrões mínimos de gasto em educação, a emenda constitucional também determinava que deveria ser estabelecido a cada ano um valor mínimo nacional de gasto por aluno, sendo este complementado pelo governo federal nos estados onde o valor mínimo nacional não fosse alcançado.

Na prática, a implementação dessa emenda constitucional implicava uma minirreforma tributária de âmbito estadual, na medida em que, a cada ano, $15 \%$ das receitas de impostos de estados e municípios seriam automaticamente retidas e contabilizadas em um fundo estadual, o FUNDEF ${ }^{18}$, e redistribuídas, no interior de cada estado, entre governos estaduais e municipais proporcionalmente ao número de matrículas oferecidas anualmente ${ }^{19}$. 
A proposta de emenda constitucional penalizava diretamente os nove estados da região Nordeste e o Rio de Janeiro, uma vez que neles a matrícula já era predominantemente municipal (ver Tabela 4). Entretanto, favorecia outros estados que ou receberiam receitas adicionais ou obteriam adesão de seus respectivos municípios para a municipalização da matrícula. Por conseqüência, a proposta do Executivo federal dividia os governadores entre "perdedores" e "ganhadores".

A estratégia formulada por técnicos do Ministério da Educação além de obter a aprovação da Presidência fez com que o Executivo federal mobilizasse sua coalizão de apoio para aprovar a emenda constitucional no Congresso. As perdas fiscais dos estados do Nordeste que provocaram a resistência de suas bancadas à aprovação da emenda - foram compensadas com a inclusão do auxílio federal ao ensino médio nos estados da região por um período de cinco anos no Projeto Alvorada.

Adicionalmente, a ausência da regra de ratificação dos estados para a aprovação de emendas à Constituição, mesmo em decisões que afetam diretamente as receitas de estados e municípios, limitou significativamente o potencial de veto dos estados e municípios diretamente penalizados pela reforma. A emenda foi aprovada e regulamentada em $1996 \mathrm{e}$ implementada a partir de $1998^{20}$.

Para o Executivo federal, a estratégia de emendar a Constituição decorreu do fato de a oferta de ensino fundamental estar distribuída entre governos estaduais e municipais, em decorrência de diferentes trajetórias estaduais de expansão dessa oferta, ocorrida particularmente entre os anos 70 e 90 . À exceção de um programa no Paraná entre meados dos anos 80 e 90, e de alguns poucos esforços no Nordeste durante o regime militar, as tentativas de municipalização por parte de governos estaduais tinham sido em geral fracassadas. Elas defrontavam-se com as resistências dos governos municipais a assumir novas atribuições. Além disso, nessa política particular, diferentemente das políticas de desenvolvimento urbano e de saúde, o governo federal não detinha a função de principal financiador, o que limitava muito seus recursos para induzir o comportamento dos governos locais.

O acelerado processo de alteração dos padrões prévios de distribuição das matrículas no âmbito dos estados, assim como de elevação 
dos salários docentes, explica-se em grande parte pelo interesse dos governos locais em aumentar suas receitas. Isto é, uma vez aprovada a emenda constitucional, aumentar a oferta de matrículas na rede de ensino fundamental passou a ser uma estratégia racional para obter receitas adicionais. Trata-se, assim, do resultado da estrutura de incentivos da nova legislação sobre a decisão dos governos subnacionais. A oferta de matrículas no ensino fundamental permitiu combinar ganhos de receita com a ampliação da oferta de serviços à população, bem como a elevação dos salários dos professores.

\section{Descentralização da Política de Saúde}

Ao longo da década de 90, o governo federal foi muito bem-sucedido em transferir para os municípios brasileiros a responsabilidade pela gestão dos serviços públicos de saúde.

A descentralização e a universalização da política federal de saúde e a conseqüente construção do Sistema Único de Saúde-SUS passaram a ser normas constitucionais na Constituição Federal de 1988. Embora o princípio do direito universal de acesso aos serviços públicos de saúde passasse a ter validade imediatamente após a promulgação da Constituição, a municipalização destes implicava um processo de reestruturação do arcabouço nacional dos serviços, cuja principal conseqüência seria a transferência de atividades até então desempenhadas no âmbito federal para os municípios ${ }^{21}$. Esse novo modelo estaria assentado na separação entre financiamento e provisão dos serviços (Costa et alii, 1999), ficando o financiamento a cargo das três esferas de governo e a provisão dos serviços sob a responsabilidade dos municípios.

A municipalização da gestão dos serviços de saúde foi o elemento central da agenda de reformas do governo federal ao longo da década de 90, e pode-se afirmar que, deste ponto de vista, a reforma foi um sucesso. Em 2000, 99\% dos municípios estavam habilitados junto ao SUS, aceitando, assim, as normas da política de descentralização do governo federal (ver Tabela 5).

A agenda da reforma tinha como objetivos universalizar o acesso aos serviços e descentralizar sua gestão, isto é, a reforma visou, simultaneamente, romper com o modelo prévio assentado sobre o princípio contributivo e transferir aos municípios responsabilidades de gestão 
Tabela 5

Habilitação dos Municípios ao SUS segundo Anos Selecionados

Brasil (1988-2000)

\begin{tabular}{l|c|c|c|c}
\hline & 1988 & 1993 & 1996 & 2000 \\
\hline Municípios Habilitados & 0 & 1.090 & 3.127 & 5.450 \\
Total de Municípios & 4.179 & 4.974 & 4.973 & 5.507 \\
\hline Habilitados/Total (\%) & 0 & 22 & 62,87 & 98,96 \\
\hline
\end{tabular}

Fontes: Dados sobre municipalização da saúde: Costa et alii (1999); Guimarães (2001). Dados sobre número de municípios: IBGE.

Obs.: Na NOB/91 foram habilitados 420 municípios, e na NOB/92, 670 (Guimarães, 2001).

da prestação de serviços, mantendo a participação federal no financiamento da política. Tratava-se, portanto, de uma reforma que envolvia o princípio ordenador do direito à saúde e o modelo centralizado de prestação de serviços.

A universalização dos serviços implicava a ampliação da abrangência de direitos dos cidadãos, uma vez que o princípio contributivo do modelo anterior excluía do acesso aos serviços camada significativa da população com baixos rendimentos ou com formas precárias de inserção no mercado de trabalho. Esse objetivo da reforma - elevar o número de beneficiários da política -, seguramente, representou um forte estímulo para a adesão dos municípios ao SUS. Os créditos políticos derivados do aumento da oferta de serviços de saúde criaram nas administrações locais incentivos para assumir sua gestão ${ }^{22}$.

No entanto, essa variável - o interesse das elites locais na visibilidade política da universalização dos serviços de saúde - não é suficiente para explicar a adesão dos municípios à política federal nem o ritmo em que esta ocorreu. O objetivo da universalização, a norma constitucional da municipalização dos serviços, a competição eleitoral e as condições institucionais para a barganha federativa já estavam presentes no cenário político brasileiro em 1988. Estes fatores explicam, por exemplo, por que o número de estabelecimentos municipais de saúde cresceu de 2.961 para 18.662 entre 1981 e 1992, passando de um percentual de $22 \%$ para $69 \%$ do total de estabelecimentos do setor público no mesmo período (Costa et alii, 1999:37).

Todavia, eles não explicam por que os municípios aceitaram a transferência da responsabilidade pela gestão dos serviços, tarefa razoavelmente mais complexa do que a sua simples oferta. Observe-se que a 
instalação de capacidades de gestão envolvia custos elevados, tendo em vista a quase ausência destas nas administrações municipais, resultado da centralização das funções no Executivo federal desde a era Vargas. Aquelas variáveis também não são suficientes para explicar por que esse processo de aceitação da transferência de responsabilidades se acelerou apenas na segunda metade dos anos 90 (ver Gráfico 1).

A adesão dos municípios ao SUS e, particularmente, o seu ritmo no plano nacional são explicados pela estratégia de descentralização do governo federal consubstanciada em portarias editadas pelo Ministério da Saúde. Os "arrancos" de adesão estão diretamente associados à edição das Normas Operacionais Básicas. A NOB/91 introduziu o princípio da habilitação ao SUS, mecanismo mediante o qual os estados e municípios poderiam aderir à política federal de descentralização, subordinando-se às regras federais e capacitando-se a receber as transferências oriundas dessa esfera de governo. Entre 1991 e 1992, sob o governo Collor, ocorreu um primeiro impulso de adesão sob as $\mathrm{NOB} / 91$ e NOB/92, que regulamentavam a sistemática de transferência de recursos para os estados e municípios. No governo Collor, entretanto, essas portarias ministeriais estabeleciam regras de trans-

\section{Gráfico 1}

Evolução da Habilitação Municipal do SUS

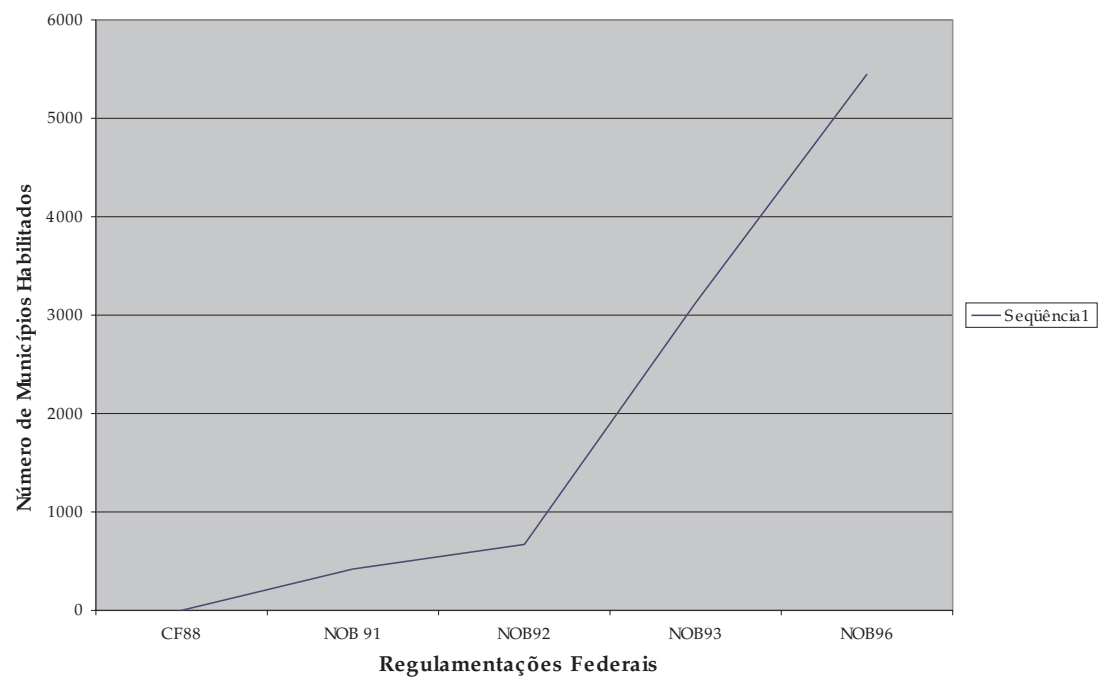


ferência de recursos que conferiam um caráter incerto e politizado às mesmas, razão pela qual a adesão municipal ao SUS, nesse período, permaneceu em 22\% (ver Tabela 5). Essas NOBs foram fortemente combatidas pelo movimento sanitarista e foram "mais conhecidas pelo que não avançaram do que pelo que implantaram" (Guimarães, 2001:49).

O segundo grande arranco, entre 1993 e 1995, ocorreu sob a vigência da NOB/93, durante o governo Itamar Franco. Resultado de um amplo processo de consulta, esta Portaria do ministro da Saúde abria um leque de escolhas aos municípios, que poderiam optar entre três modalidades distintas de habilitação de acordo com suas capacidades administrativas, vindo a receber recursos federais diretamente vinculados às funções de gestão assumidas. Nesse segundo momento, ainda marcado pela incerteza quanto à capacidade de o Ministério da Saúde efetivamente realizar a totalidade das transferências por causa da escassez de recursos, $63 \%$ dos municípios brasileiros aderiram ao SUS ${ }^{23}$.

O processo de municipalização completou-se sob a NOB/96, cuja implantação ocorreu somente a partir de 1998. A adesão dos municípios foi superior às metas do próprio Ministério da Saúde. Duas são as principais razões para este resultado. Em primeiro lugar, as novas regras de transferência federais acrescentavam recursos aos cofres de $66 \%$ dos municípios brasileiros e eram fiscalmente neutras para $22 \%$ deles (Costa et alii, 1999:45). Em segundo, o Ministério da Saúde fez crer que as transferências seriam efetivamente realizadas.

No caso da política de saúde, a passagem da fase de definição dos objetivos da reforma para a etapa de implementação implicou um deslocamento da principal arena decisória: do Parlamento para o Executivo, transferindo poder decisório para as burocracias deste último. As determinações constitucionais já haviam sido estabelecidas em 1988, cabendo ao Ministério da Saúde a edição de normas operacionais para colocar em prática o processo de transferência de funções a estados e municípios.

Entretanto, os conflitos com o Executivo federal durante o governo Collor tornaram visível ao movimento sanitarista - principal articulador do processo de descentralização - que a concentração de recursos de autoridade no Ministério da Saúde - via funções de financiamento e de coordenação das relações intergovernamentais - limitava 
a representação de interesses de estados e municípios na arena decisória de formulação e implementação da reforma. No governo Itamar Franco, a oportunidade institucional oferecida por um ministro com fortes ligações com o movimento sanitarista, Jamil Haddad, permitiu a institucionalização de uma arena federativa para a formulação da política de saúde: todas as medidas da descentralização deveriam ser aprovadas por uma Comissão Intergestores Tripartite, composta por representantes dos Executivos federal, estaduais e municipais. A constituição dessa arena federativa permitiu a incorporação parcial das demandas dos governos locais às regras da política federal. Assim, as portarias editadas pelo Ministério da Saúde adaptaram sucessivamente as regras de operação da política para obter a adesão dos municípios.

O conteúdo das sucessivas normas operacionais expressa um processo de aprendizagem (policy-learning) no âmbito das burocracias do Ministério da Saúde. Por seu intermédio, foram alteradas, no prazo de menos de uma década, as regras da política federal de descentralização, sem que fossem modificados seus instrumentos e nem sequer seus objetivos. Neste processo, a burocracia do Ministério da Saúde incorporou não só demandas dos atores com potencial capacidade de veto à política federal (particularmente estados e municípios), como também a participação institucionalizada desses atores na formulação das regras federais.

\section{CONCLUSÕES}

Nos quatro casos de política social aqui analisados, o governo federal alcançou diferentes graus de sucesso, mas, à exceção da privatização das empresas estaduais de saneamento, não encontrou obstáculos intransponíveis para implementar sua agenda de reformas.

Os casos apresentados revelam, em primeiro lugar, que não existe relação necessária entre a radicalidade das reformas pretendidas pelo Executivo federal e a arena decisória em que são aprovadas as medidas indispensáveis à sua implementação. Reformas radicais e profundas no modelo de uma política pública não implicam, obrigatoriamente, que as decisões que lhe são correlatas devam ser tomadas em uma arena decisória cujos custos de aprovação sejam mais elevados para o Executivo federal - como, por exemplo, a aprovação de reformas constitucionais no Congresso. Das quatro políticas em tela, em 
apenas uma - a municipalização da educação básica - a aprovação de uma emenda constitucional foi a estratégia adotada pelo governo federal.

Os quatro casos têm em comum o fato de o sucesso das reformas depender da capacidade do Executivo federal para superar o poder de veto à implementação de políticas decorrente da baixa integração vertical de estados federativos. Em razão da sua autonomia política e fiscal, os governos subnacionais adotam as políticas federais apenas por adesão voluntária ou obrigação constitucional. Nas quatro políticas, verifica-se que o governo federal excluiu a possibilidade de atribuir competências exclusivas ou obrigações constitucionais aos governos subnacionais, buscando a aprovação de medidas cuja estrutura de incentivos tornasse atraente a subordinação de estados e/ou municípios a seus objetivos de reforma.

A estratégia do Executivo federal, em cada política particular, foi condicionada pelos objetivos da reforma e pelo modo como estavam estruturadas as relações intergovernamentais, que, por sua vez, são condicionadas por regras constitucionais, legado de políticas anteriores e o ciclo da política.

No caso da educação fundamental, o objetivo da reforma envolvia a intervenção em distintas configurações estaduais de distribuição de matrículas e nos sistemas de pagamento de professores. Dado que a oferta de serviços era, e ainda é, inteiramente controlada por estados e municípios e o Executivo federal estava insuficientemente dotado de recursos para influir nas escolhas dos governos locais - tais como o papel de financiador nas políticas de saúde e desenvolvimento urbano-, a realização de uma minirreforma tributária de âmbito estadual, via aprovação de uma emenda constitucional, foi a estratégia adotada. Esta minirreforma afetava diretamente as receitas fiscais dos estados da região Nordeste, o que não impediu, todavia, sua aprovação, tendo esta sido viabilizada graças ao poder de agenda e ao uso de recursos à disposição do presidente, à coalizão de apoio parlamentar do Executivo federal e à ausência da regra de ratificação dos estados para emendas constitucionais no Brasil. Tais características do presidencialismo e do federalismo brasileiros deslocaram para a arena do Poder Executivo a parte mais importante do processo de formulação da reforma, tal como previsto por Immergutt (1996) para os Estados unitários e parlamentaristas. Uma vez aprovada a emenda, a adesão 
dos governos locais foi um resultado direto dos incentivos fiscais embutidos nas regras de operação da nova política.

A descentralização da atenção à saúde não envolvia uma reforma constitucional, mas a obtenção da adesão dos municípios a normas constitucionais já aprovadas em 1988. Neste caso, a estratégia passou pela edição de um conjunto sucessivo de portarias ministeriais, a partir das quais a burocracia do Ministério da Saúde foi progressivamente organizando uma estrutura de incentivos destinada a obter a adesão dos municípios aos objetivos da reforma. A estratégia foi em grande parte condicionada pelas possibilidades de veto dos municípios à implementação das medidas pretendidas. A fase de implementação, combinada às funções do Ministério da Saúde, transformou o Executivo federal na principal arena decisória, muito embora tenha sido institucionalizada uma arena federativa, através da qual os interesses e a representação de estados e municípios foram incorporados ao processo de formulação das regras federais.

Finalmente, a desestatização progressiva das empresas públicas de habitação, assim como a modificação radical da política federal de habitação, foram resultado de uma estratégia de desfinanciamento - via mudança das exigências legais para obtenção de financiamentos federais - bem como da gestão seletiva da liberação de recursos federais. No que se refere às políticas de habitação e saneamento, a arena decisória para a aprovação das medidas de reforma não incluía a representação de estados e municípios, o que favoreceu a aprovação dos objetivos de reforma do Executivo federal. Formulada a estratégia pela burocracia do Ministério do Planejamento e Orçamento, os obstáculos institucionais seriam praticamente irrelevantes.

Conforme vimos, a aprovação de medidas no Congresso é uma das etapas de um processo de reformas. Uma vez aprovada uma legislação reformadora na arena parlamentar, sua implementação envolve a adoção de medidas que deslocam para a arena do poder Executivo federal a autoridade decisória sobre o conteúdo das políticas a serem efetivamente concretizadas. Isto significa que as burocracias encarregadas da implementação das reformas aprovadas passaram a dispor de inúmeras oportunidades institucionais para tomar decisões independentemente de autorização legislativa. Posteriormente à aprovação legislativa, essas burocracias têm autoridade para traduzir leis 


\section{em políticas efetivas, simplesmente pela definição das regras de im- plementação das políticas.}

(Recebido para publicação em novembro de 2001)

\section{NOTAS}

1. Weir et alii (1988) demonstram o papel da estrutura federativa dos EUA na emergência do sistema de proteção social norte-americano. Pierson (1994) mostra como as instituições federais foram um obstáculo às reformas descentralizadoras de Reagan.

2. Além do poder para aprovar todas as leis e emendar a Constituição, a Câmara Alta dispõe de doze áreas de exclusividade legislativa (Stepan, 1999).

3. O controle dos governos locais sobre a sobrevivência eleitoral dos candidatos ao Legislativo federal seria o mecanismo através do qual os governos subnacionais controlariam o comportamento parlamentar no Congresso (Abrucio, 1998; Stepan, 1999; Samuels, 2000; Ames, 2001).

4. Para um exemplo, ver Mansbridge (1986), que analisa as razões pelas quais o Equal Rights Movement - ERA fracassou em aprovar a emenda constitucional que garantiria direitos iguais a homens e mulheres. Embora tenha sido aprovada no Senado dos Estados Unidos com uma votação de 84 contra 9, e diversas pesquisas de opinião tenham revelado forte apoio da opinião pública à emenda constitucional, esta não foi aprovada porque em apenas 35 estados as Casas Legislativas a aprovaram, quando seria necessário que 38 estados o tivessem feito.

5. Agradeço a compreensão da importância da distinção entre federalismo e estruturação das relações intergovernamentais à insistência de Celina Souza. Para uma discussão sobre o tema, ver Souza (2002).

6. Para uma análise sobre as reformas constitucionais recentes no Brasil, com base em estudos de caso que consideram as variáveis específicas das arenas decisórias, ver Melo (2002).

7. O conceito de paradigma de política é de Peter Hall (1993), que compreende simultaneamente a hierarquia de objetivos de uma política, bem como seus instrumentos de operação.

8. Por efeito não desejado da política anterior, existem ainda centenas de companhias municipais de saneamento.

9. O emprego de recursos do FGTS para obter apoio no Congresso pelo presidente Sarney na Constituinte e pelo presidente Collor no episódio do impeachment são os exemplos mais citados.

10. Segundo decisões anteriores do Conselho Curador do FGTS, instância colegiada federal, os recursos do Fundo deveriam ser aplicados de modo a destinar $60 \%$ para 


\section{Marta Arretche}

habitação popular e $40 \%$ para as áreas de saneamento básico e infra-estrutura urbana. Cada unidade da federação deveria ter um orçamento anual, calculado com base na arrecadação líquida do Fundo e em critérios de distribuição entre os estados que atribuem pesos distintos às variáveis arrecadação do FGTS, população urbana e déficit habitacional e de água e esgoto. Este orçamento estabelece o valor máximo que pode ser emprestado para cada estado anualmente.

11. Entrevista com dirigente da Associação Brasileira de COHABS - ABC. As COHABS do Ceará, Alagoas, Rondônia, Rio Grande do Norte, Pernambuco, Espírito Santo, Mato Grosso e Goiás foram fechadas. A СоHAB do Rio Grande do Sul havia declarado falência antes de 1995. As empresas estaduais da Bahia, Distrito Federal e Rio de Janeiro transformaram-se em agências de desenvolvimento urbano.

12. Na verdade, a natureza das relações entre os governadores e as burocracias das empresas estaduais de saneamento foi um fator determinante na definição das estratégias estaduais de privatização ou preservação das empresas estaduais de saneamento. Ver, a este respeito, Arretche (1999).

13. “Artigo 30 - Compete aos Municípios: [...] V - Organizar e prestar, diretamente ou sob regime de concessão ou permissão, os serviços públicos de interesse local, incluído o de transporte coletivo, que tem caráter essencial".

14. No Rio de Janeiro, após uma longa batalha jurídica e política que consumiu quase a totalidade do governo Marcelo Alencar, o consórcio privado interessado na compra da empresa desistiu da operação por causa das incertezas quanto à possibilidade de poder vir a operar efetivamente a companhia.

15. Leis 7.839/89, 88.036/90 e Decreto 99.684/90.

16. Agradeço a Fernando Limongi e Eduardo Marques a sugestão para a importância do caráter não federativo dessa arena decisória.

17. Na verdade, o Conselho Curador em diversas situações aprovou ad hoc medidas de aplicação de recursos já implementadas pela Caixa Econômica Federal, as quais contrariavam regulamentações prévias do próprio Conselho (USP/EESC/FIPAI, 2000). Além disso, a própria representação da Central Única dos Trabalhadores CUT aderiu à estratégia de reforma da burocracia do Ministério do Planejamento e Orçamento.

18. As receitas do Fundo de Participação dos Municípios - FPM, Imposto sobre Circulação de Mercadorias - ICMS e Imposto sobre Produtos Industrializados Proporcional às Exportações - IPI/Exp são automaticamente bloqueadas quando da realização dos créditos.

19. O número de matrículas oferecidas é calculado anualmente através do Censo Escolar.

20. É por essa razão que seu impacto se inicia depois de 1997.

21. O artigo 30 da Constituição de 1988 estabelece que o município é o único ente federado a quem é atribuída a missão constitucional de prestar serviço de atendimento à saúde da população.

22. Pesquisas de opinião revelam ser significativa a satisfação dos brasileiros com relação a esses serviços (Costa et alii, 1999:50). A literatura comparada aponta que o interesse dos governos na visibilidade da responsabilidade pela oferta de benefícios sociais foi historicamente uma das razões de sua expansão. Pierson (1994) demons- 
tra que, no contexto de expansão do welfare state, a concentração da autoridade política implica a concentração da accountability pela ampliação de benefícios. Banting (1995) demonstra que, no Canadá, a disputa entre governo federal e províncias pelos créditos políticos derivados da ampliação de serviços sociais contribuiu para a expansão do welfare state canadense.

23. Em 1994, o ministro Antonio Britto (do Ministério da Previdência e Assistência Social) suspendeu as transferências constitucionais de $30 \%$ dos recursos do Fundo da Previdência e Assistência Social para o Ministério da Saúde, abrindo uma crise de desfinanciamento no setor.

\section{REFERÊNCIAS BIBLIOGRÁFICAS}

ABRUCIO, Fernando Luiz. (1998), Os Barões da Federação. São Paulo, USP/Hucitec.

AMES, Barry. (2001), The Deadlock of Democracy in Brazil. Ann Arbor, University of Michigan Press.

ARRETCHE, Marta T. S. (1999), “Política Nacional de Saneamento: A Reestruturação das Companhias Estaduais", in Temas Especiais - Infra-Estrutura. Perspectivas de Reorganização. IPEA, Brasília.

BANTING, Keith G. (1995), “The Welfare State as Statecraft”, in P. Pierson e S. Leibfried (eds.), European Social Policy. Between Fragmentation and Integration. Washington, Brookings Institution.

COSTA, N. R., SILVA, P. L. B. e RIBEIRO, José Mendes. (1999), “A Descentralização do Sistema de Saúde no Brasil”. Revista do Serviço Público, ano 50, no 3, pp. 33-56.

DUCHACEK, Ivo. (1970), Comparative Federalism. The Territorial Dimension of Politics. Santa Barbara, Holt, Rinehart and Winston Inc.

FIGUEIREDO, Argelina e LIMONGI, Fernando. (1999), Executivo e Legislativo na Nova Ordem Constitucional. Rio de Janeiro/São Paulo, FGV / ANPOCs.

_. (2002), “Incentivos Eleitorais, Partidos e Política Orçamentária". Dados, vol. 45, no 2, pp. 303-344.

GUIMARÃES, Luisa. (2001), Arquitetura da Cooperação Intergovernamental: Os Consórcios em Saúde de Mato Grosso. Dissertação de Mestrado, Escola Nacional de Saúde Pública/Fundação Oswaldo Cruz, Rio de Janeiro.

HALL, Peter. (1993), "Policy Paradigms, Social Learning, and the State. The Case of Economic Policymaking in Britain". Comparative Politics, vol. 25, nº 3, pp. 275-296.

IMMERGUTT, Ellen M. (1996), “As Regras do Jogo: A Lógica da Política de Saúde na França, na Suíça e na Suécia". Revista Brasileira de Ciências Sociais, vol. 11, no 30, pp. 139-163. 


\section{Marta Arretche}

LIJPHART, Arend. (1984), Democracies. Patterns of Majoritarian and Consensus Government in Twenty-One Countries. New Haven, Yale University Press. . (1999), Patterns of Democracy: Government Forms and Performance in Thirty-Six Countries. New Haven, Yale University Press.

MAINWARING, Scott. (1997), “Multipartism, Robust Federalism, and Presidentialism in Brazil", in S. Mainwaring e M. S. Shugart (eds.), Presidentialism and Democracy in Latin America. New York, Cambridge University Press.

MANSBRIDGE, Jane J. (1986), Why We Lost the Era? Chicago/London, University of Chicago Press.

MELO, Marcus André. (2002), Reformas Constitucionais no Brasil. Rio de Janeiro, Revan.

PIERSON, Paul. (1994), Dismantling the Welfare State? Reagan, Thatcher, and the Politics of Retrenchment. Cambridge, Cambridge University Press.

_ e LEIBFRIED, Stephan (eds.). (1995), European Social Policy. Between Fragmentation and Integration. Washington, Brookings Institution.

PINHEIRO, Maurício M. Saboya. (1998), “Fundos de Poupança Compulsória e Financiamento da Economia". Textos para Discussão, n 5ㅛ, IPEA.

SAMUELS, David. (2000), “Concurrent Elections, Discordant Results. Presidentialism, Federalism, and Governance in Brazil". Comparative Politics, vol. 33, nํ1, pp. 1-20.

SANCHEZ, Oscar Adolfo. (2000), Águas de São Paulo. Um Estudo sobre as Tentativas de Privatização do Saneamento (1995-1998). Dissertação de Mestrado, FFLCH/USP, São Paulo.

SEMEGHINI, Ulysses Cidade. (s/d), FUNDEF: Corrigindo Distorções Históricas. Manuscrito.

SOUZA, Celina. (2002), "Brazil: The Prospects of a Center-Constraining Federation in a Fragmented Polity". Publius: The Journal of Federalism, vol. 32, no 2, pp. 23-48.

STEPAN, Alfred. (1999), "Para uma Nova Análise Comparativa do Federalismo e da Democracia: Federações que Restringem ou Ampliam o Poder do Demos". Dados, vol. 42, nํ2, pp. 197-251.

TSEBELIS, George. (1997), “Processo Decisório em Sistemas Políticos: Veto Players no Presidencialismo, Parlamentarismo, Multicameralismo e Pluripartidarismo". Revista Brasileira de Ciências Sociais, vol. 12, nº 34, pp. 89-117.

USP/EESC / FIPAI. (2000), Projeto Desenvolvimento de Metodologia de Avaliação dos Programas de Aplicação dos Recursos do FGTS. São Paulo. Manuscrito.

WEAVER, K. R. e ROCKMAN, B. (1993), Do Institutions Matter? Washington, Brookings Institution.

WEIR, M., ORLOFF, A. S. e SKOCPOL, T. (1988), The Politics of Social Policy in the United States. Princeton, Princeton University Press. 


\begin{abstract}
Federalism and Inter-Governmental Relations in Brazil: Social-Program Reforms
\end{abstract}

The article analyses the process of reform in four areas of social policies that affect directly the interests of sub-national governments: basic education, social housing programs, basic sanitation and health. As the study reveals, despite the varying degree of success achieved in the various policy initiatives and contrary to the expectations of the prevailing interpretations of the nature of Brazilian federalism, the federal government faced no insurmountable hurdles in implementing their reform agenda. The study aims at demonstrating that (i) in the absence of any constitutional mandatory requirement, the political autonomy of local governments - typical of federative States - actually enhances the veto power of local governments over policy initiatives proposed by the federal Executive branch. However, (ii) power resources available to the federal Executive branch - such as agenda definition and vetoing powers - in addition to control over resources that are essential to the political survival of the representatives increase the chances of success of the federal government. Furthermore, (1999), (iii) the constitutional authority of Brazilian states is far more limited than that of the North-American states; (iv) the category "federalism", however, is not sufficient to define the potential stability of specific policies, which depends upon how inter-governmental relations are structured in each particular policy. Specifically, (v) constitutional rules, legacies from previous policies and the political cycle frame the decision arenas in various ways, thus conditioning both the strategies and chances of success of the federative players.

Keywords: federalism; inter-governmental relations; social policies 


\section{RÉSUMÉ}

Fédéralisme et Relations Intergouvernementales au Brésil: La Réforme des Programmes Sociaux

Dans cet article, on analyse le processus de réforme dans quatre domaines de la politique sociale atteignant directement les intérêts des gouvernements régionaux: éducation élémentaire, logement social, assainissement éssentiel et santé. On y voit que le gouvernement fédéral a réussi dans ces domaines à différents degrés, mais que, contrairement à l'attente des interprétations dominantes sur la nature du fédéralisme brésilien, il n'a pas trouvé d'obstacles infranchissables à la mise en place de son programme de réformes. Ici on essaie de montrer que (i) en l'absence de contraintes issues de la Constitution, l'autonomie politique des gouvernements locaux - propre aux États d'une fédération - rend effectivement plus puissant le veto que ces gouvernements locaux opposent à la mise en place de politiques proposées par le gouvernement fédéral. Cependant, (ii) les ressources du pouvoir de l'exécutif fédéral, tels que le pouvoir de fixer les priorités et d'opposer des vetos, ainsi que le contrôle des fonds nécessaires à l'existence politique des parlementaires favorisent plutôt le gouvernement fédéral. De surcroît, (1999), (iii) l'autorité constitutionnelle des États brésiliens est bien plus réduite que celle des États nord-américains. Cependant, (iv) la catégorie "fédéralisme" ne suffit pas pour définir le potentiel de stabilité des politiques particulières. Ce potentiel est soumis à la manière dont sont structurées les relations intergouvernementales dans les politiques particulières. En particulier (v) des règles constitutionnelles, héritées de politiques précédentes ainsi que les cycles de la politique structurent différemment les arènes de décisions, déterminant les stratégies et les chances de succès des acteurs fédératifs.

Mots-clé: fédéralisme; relations intergouvernementales; politiques sociales 